\title{
Desempenho de sementes de soja submetidas a diferentes potenciais osmóticos em polietilenoglicol
}

\author{
Soybean seed performance submitted to different osmotic potentials in polietileneglycol
}

\author{
Josué Bispo da Silva ${ }^{1}$ Teresinha de Jesus Deléo Rodrigues ${ }^{2}$ Roberval Daiton Vieira $^{3}$
}

\begin{abstract}
- NOTA-
RESUMO

Com o objetivo de determinar o potencial fisiológico e o desempenho germinativo de sementes de soja, dois lotes foram avaliados pelos testes de germinação, de frio, de envelhecimento acelerado, de condutividade elétrica e de

under osmotic stress was submitted to regression analysis. The osmotic stress in polietileneglycol, in potential equal or smaller than -0.6MPa, is a promising procedure to evaluate the physiological potential of soybean seeds; decreasing values of osmotic stress reduce germination, while osmotic stress level nearby zero may cause seeds invigoration.
\end{abstract} germinação sob estresse osmótico, nos potenciais 0,0 (controle); $-0,1 ;-0,2 ;-0,3 ;-0,4 ;-0,5 ;-0,6$ e -0,7MPa. Utilizou-se delineamento inteiramente casualizado e quatro repetições de 50 sementes, exceto para a condutividade elétrica, com duas repetições de 50 sementes. Adicionalmente, a germinação sob estresse osmótico foi submetida à análise de regressão. O estresse osmótico em polietilenoglicol, em potencial igual ou inferior a -0,6MPa, é um procedimento promissor para a avaliação do potencial fisiológico de sementes de soja; valores decrescentes de potencial osmótico reduzem a germinação, enquanto potenciais próximos a zero podem provocar o envigoramento das sementes.

Palavras-chave: potencial fisiológico, estresse hídrico, germinação.

\section{ABSTRACT}

With the aim at determining the physiological potential and germinative performance of soybean seeds, two lots were evaluated by germination, cold, accelerated aging, electrical conductivity tests and osmotic stress, at potentials 0.0 (control), -0.1, -0.2, -0.3, -0.4, -0.5, -0.6 and -0.7MPa. The experimental design used was completely randomized, with four replicates of 50 seeds, except to electrical conductivity, with two replicates of 50 seeds. Additionally, the germination
Key words: physiological potential, water stress, germination.

No Brasil, períodos de estiagem que ocorrem, com freqüência, por ocasião da implantação da cultura da soja são uma das causas mais comuns do baixo percentual de germinação e emergência das plântulas em campo (PESKE \& DELOUCHE, 1985). Aredução da atividade enzimática que se verifica na condição de umidade abaixo do exigido pela cultura é uma das causas da baixa germinação de sementes e da velocidade em que ela ocorre (BEWLEY \& BLACK, 1994).

Em face desses problemas, torna-se necessária a utilização de procedimentos adequados para a determinação do potencial fisiológico dos lotes de sementes. Diversos testes estão sendo executados com essa finalidade, em sementes de soja, como o de envelhecimento acelerado, de frio, de condutividade elétrica e de estresse osmótico, todos apresentando resultados satisfatórios. Com esses testes, as empresas

\footnotetext{
${ }^{1}$ Programa de Pós-graduação em Produção e Tecnologia de Sementes,Universidade Estadual Paulista (UNESP), Campus de Jaboticabal, 14844-900, Jaboticabal, São Paulo, Brasil. E-mail: jbsilva@fcav.unesp.br. Autor para correspondência.

${ }^{2}$ Departamento de Biologia Aplicada à Agropecuária, UNESP, Jaboticabal, São Paulo, Brasil.

${ }^{3}$ Departamento de Produção Vegetal, UNESP, Jaboticabal, São Paulo, Brasil.
} 
produtoras de sementes procuram detectar lotes com desempenho superior, capazes de germinar em condições de estresse ambiental, tal como estiagem na época de semeadura.

A germinação de sementes de soja em ambiente com restrição hídrica, como em solução com Polietilenoglicol - PEG 6000, pode ser considerada um procedimento promissor, como também são o envelhecimento acelerado e o teste de frio. Neste caso, não há ainda consenso quanto às condições hídricas sob as quais o processo germinativo de sementes de soja é inibido. A avaliação do desempenho germinativo sob condições de estresse osmótico, em potenciais que variaram de 0,0 a -1,5MPa, permitiu concluir que a resposta das sementes é influenciada, entre outros fatores, pelo seu vigor (SANTOS et al., 1992; BRACCINI et al., 1996; MORAES \& MENEZES, 2003).

Na condução desse procedimento, diversos compostos químicos têm sido utilizados na simulação de estresse hídrico, dentre eles o polietilenoglicol, agente osmótico sem efeitos adversos para sementes de soja, por ser quimicamente inerte, não-tóxico, de elevado peso molecular e, portanto, de difícil absorção, e que tem proporcionado restrição hídrica a sementes, dependendo da concentração (BRACCINI et al., 1996; MORAES \& MENEZES, 2003).

O objetivo do trabalho foi avaliar o desempenho germinativo e o potencial fisiológico de sementes de soja provenientes de dois lotes, usando vários testes e sob diferentes condições de potenciais osmóticos.

Para o trabalho experimental, utilizaram-se sementes de soja da variedade M-Soy 8411, provenientes de dois lotes colhidos nas safras agrícolas 2000 e 2001. O teste de germinação foi conduzido com quatro repetições de 50 sementes de cada lote (BRASIL, 1992). No teste de frio, utilizaram-se quatro repetições de 50 sementes, semeadas entre três folhas de papel germitest, e mantidas em sacos plásticos a $10^{\circ} \mathrm{C}$, durante sete dias; na seqüência, os sacos foram abertos e os rolos colocados em germinador a $25^{\circ} \mathrm{C}$ por quatro dias (BARROS et al., 1999). No teste de envelhecimento acelerado, quatro repetições de $42 \mathrm{~g}$ de sementes por lote foram colocadas em caixas plásticas de germinação, em camada única, sobre uma tela, e mantidas a $42^{\circ} \mathrm{C}$ por 48 horas (MARCOS FILHO, 1999). Para o teste de condutividade elétrica, as massas de duas repetições de 50 sementes por lote foram determinadas em balança de precisão (0,001 g) e, em seguida, imersas em $75 \mathrm{~mL}$ de água desionizada e mantidas a $25^{\circ} \mathrm{C}$ por 24 horas (VIEIRA \& KRZYZANOWSKI, 1999).

Para a germinação sob estresse osmótico com polietilenoglicol - PEG 6000, foram utilizados os potenciais 0,0 (controle); - 0,$1 ;-0,2 ;-0,3 ;-0,4 ;-0,5 ;-0,6$ e -0,7MPa (VILLELA et al., 1991). Quatro repetições de 50 sementes por lote foram colocadas em caixas plásticas de germinação sobre papel de filtro, umedecido com solução na proporção de 2,5 vezes a massa do papel seco, e mantidas em germinador a $25^{\circ} \mathrm{C}$, durante oito dias, com troca diária das soluções.

$\mathrm{Na}$ análise estatística dos testes de germinação, de envelhecimento acelerado, de frio, de condutividade elétrica, e na avaliação do desempenho das sementes sob estresse osmótico, utilizou-se delineamento inteiramente ao acaso e as médias foram comparadas pelo Teste de Tukey, em nível de 5\% de probabilidade de erro. No teste de estresse osmótico, a análise foi feita separadamente para cada potencial osmótico, o desempenho de cada lote analisado por meio de regressão e os resultados apresentados na forma de figura.

Os lotes 1 e 2 apresentaram-se semelhantes, quando avaliados pelo teste de germinação (Tabela 1 ). No entanto, nos testes de condutividade elétrica, de frio e de envelhecimento acelerado, o lote 2 apresentou potencial fisiológico inferior. O teste de germinação, por ser conduzido sob condições totalmente favoráveis para a espécie, não é capaz de indicar o real estado de deterioração em que as sementes encontram-se, podendo, segundo MARCOS FILHO (1999), superestimar o potencial fisiológico destas.

Em condições de estresse osmótico (Tabela 1), o lote 2 apresentou-se inferior ao 1 , nos potenciais -0,6 e -0,7MPa, confirmando o resultado obtido nos testes de primeira contagem, de frio, de envelhecimento acelerado e de condutividade elétrica. SANTOS et al. (1996) também conseguiram separar genótipos de soja em níveis de vigor, por meio desse procedimento, nos potenciais -0,9 e -1,2MPa. A sugestão desses autores de se avaliar diferentes genótipos utilizando baixos potenciais osmóticos no substrato de germinação apresentou bons resultados também quando se utilizaram lotes de mesma variedade, visto que esse procedimento indicou diferenças entre os lotes quanto ao potencial fisiológico.

Redução mais intensa no desempenho germinativo no lote 1 ocorreu com o potencial -0,7MPa, ao passo que, no lote 2, foi em -0,6MPa e, de forma mais drástica, em -0,7MPa. Essas informações são complementadas pela representação gráfica das equações de regressão da germinação (Figura 1), na qual o lote 1 , que no potencial zero foi de $98 \%$, atingiu o máximo da função (100\%) no potencial de $0,21 \mathrm{MPa}$, decrescendo a partir de então, chegando a $87 \%$ em -0,7MPa. Já no lote 2, cuja germinação no potencial 0,0 (controle) foi de $96 \%$, o máximo da função 
Tabela 1 - Valores de condutividade elétrica (CE) e desempenho germinativo de sementes de soja de dois lotes, variedade M-Soy 8411, nos testes de germinação (G), de frio (F), de envelhecimento acelerado (EA) e submetidas a estresse osmótico em diferentes potenciais, obtidos com PEG 6000 (Jaboticabal, 2005).

\begin{tabular}{|c|c|c|c|c|c|c|c|c|c|c|c|c|}
\hline \multirow[t]{2}{*}{ Lote } & \multirow{2}{*}{$\begin{array}{c}\mathrm{CE} \\
\mu \mathrm{S} \mathrm{cm}^{-1} \mathrm{~g}^{-1}\end{array}$} & \multirow[t]{2}{*}{ G } & \multirow[t]{2}{*}{$\mathrm{F}$} & \multirow[t]{2}{*}{ EA } & \multicolumn{8}{|c|}{ Potencial osmótico (MPa) } \\
\hline & & & & & 0,0 & $-0,1$ & $-0,2$ & $-0,3$ & $-0,4$ & $-0,5$ & $-0,6$ & $-0,7$ \\
\hline & & \% & & & & & & & & & & \\
\hline 1 & 46,3b & $98 a$ & 93a & $97 a$ & $98 a$ & $99 a$ & $99 a$ & $99 a$ & $99 a$ & $98 \mathrm{a}$ & 93a & $86 a$ \\
\hline 2 & $75,1 \mathrm{a}$ & $95 a$ & $88 \mathrm{~b}$ & $67 b$ & $96 a$ & $95 a$ & $94 a$ & $94 a$ & $94 a$ & $93 a$ & $80 \mathrm{~b}$ & $66 b$ \\
\hline Média & 60,7 & 97 & 90 & 82 & 97 & 97 & 97 & 97 & 97 & 96 & 87 & 76 \\
\hline $\mathrm{CV}$ & 3,3 & 1,8 & 2,4 & 3,1 & 1,7 & 1,8 & 1,9 & 1,8 & 2,0 & 2,1 & 2,7 & 2,9 \\
\hline
\end{tabular}

Médias não seguidas por mesmas letras na coluna diferem entre si pelo teste de Tukey, em nível de 5\% de probabilidade de erro.

(98\%) ocorreu em -0,19MPa, com menor valor (69\%) também no menor potencial osmótico. Nesse lote, a germinação foi inferior a $80 \%$ a partir de $-0,59 \mathrm{MPa}$. SANTOS et al. (1996) verificaram aumento no percentual germinativo das sementes de soja, em potenciais entre -0,3 e -0,6MPa.

A justificativa provável para o aumento no percentual germinativo está no fato de que a pequena redução no potencial osmótico, de zero para -0,19 ou -0,21MPa, teria minimizado o efeito do dano ao embrião, causado pela rápida embebição das sementes (BEWLEY \& BLACK, 1994), o que estabelece um forte gradiente de potencial hídrico entre a semente e o substrato. Isso pode ter ocorrido principalmente no lote 2, que tem potencial fisiológico inferior e, consequentemente, maior grau de deterioração. No entanto, quando o déficit hídrico aumentou, a

germinação voltou a cair, e de forma mais acentuada nesse lote. BRADFORD (1990) explica que, nessas condições, as sementes têm água suficiente para iniciar o processo germinativo, momento conhecido como Fases I e II (BEWLEY \& BLACK, 1994), sem, contudo, iniciar o crescimento da raiz primária, a chamada Fase III. Uma vez que o alongamento e o processo de síntese da parede celular são altamente sensíveis à deficiência hídrica (WENKERT et al., 1978), o decréscimo no desenvolvimento pode ser devido ao baixo turgor dessas células (BRADFORD, 1995), causado por níveis crescentes de restrição hídrica. No trabalho de SANTOS et al. (1992), os maiores potenciais osmóticos também melhoraram o desempenho de sementes de soja de baixo vigor.

De um modo geral, a germinação das sementes dos lotes 1 e 2 começou a ser reduzida a partir dos potenciais de $-0,21$ e $-0,19 \mathrm{MPa}$, respectivamente. O

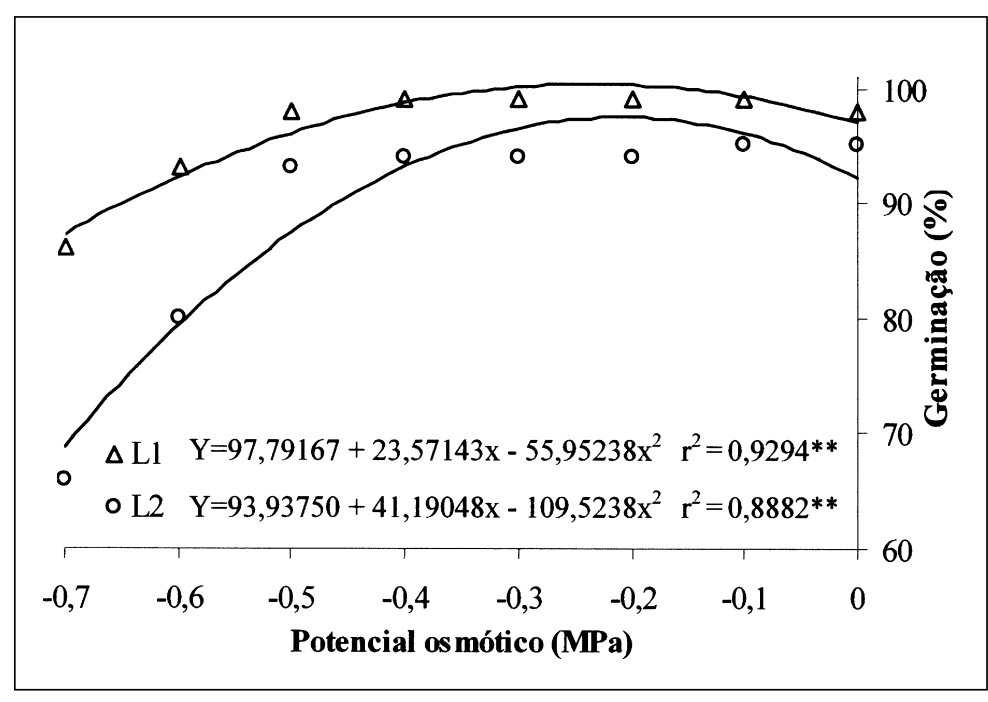

Figura 1 - Desempenho germinativo de sementes de soja sob estresse osmótico em polietilenoglicol - PEG 6000, dos lotes 1 (L1) e 2 (L2) (Jaboticabal, 2005). decréscimo na germinação de sementes submetidas à restrição de água reside também no fato de que, nessas condições, o prolongamento da fase estacionária do processo de embebição, devido à redução da atividade enzimática, leva a um menor desenvolvimento meristemático e, conseqüentemente, a atraso na protrusão da raiz primária (FALLERI, 1994). Outra causa provável para essa redução, segundo MAYER \& POLJAKOFF-MAYBER (1989), é a falta de energia para o início da germinação, já que tal energia é obtida a partir de incrementos na taxa respiratória das sementes após a embebição, que ocorre de forma mais lenta na presença de potenciais osmóticos muito baixos. 
Os resultados confirmam a possibilidade da utilização do estresse osmótico na avaliação do potencial fisiológico de sementes de soja. Esse procedimento pode ser adotado como um complemento às informações geradas por outros testes de vigor, conferindo maior segurança às empresas quanto ao destino dos lotes na etapa de comercialização.

Nas condições do presente trabalho, é possível concluir que o estresse osmótico em polietilenoglicol, em potenciais iguais ou inferiores a 0,6MPa, é um procedimento promissor para a avaliação do potencial fisiológico de sementes de soja. Valores decrescentes de potencial osmótico reduzem a germinação, enquanto potenciais próximos a zero podem provocar o envigoramento das sementes.

\section{REFERÊNCIAS}

BARROS, A.S. et al. Testes de frio. In: KRZYZANOWSKI, F.C. et al. Vigor de sementes: conceitos e testes. Associação brasileira de tecnologia de sementes. Comitê de vigor de sementes. Londrina: ABRATES, 1999. Cap.5, p.1-15.

BEWLEY, J.D.; BLACK, M. Seeds: physiology of development and germination. New York: Plenum, 1994. 445p.

BRACCINI, A.L. et al. Germinação e vigor de sementes de soja sob estresse hídrico induzido por soluções de cloreto de sódio, manitol e polietilenoglicol. Revista Brasileira de Sementes, v.18, n.1, p.10-16, 1996.

BRADFORD, K.J. A water relation analysis of seed germination rates. Plant Physiology, v.94, n.2, p.840-849, 1990.

BRADFORD, K.J. Water relations on seed germination. In: KIGEL, J.; GALILI, G. Seed development and germination. New York: Marcel Dekker, 1995. p.351-396.

BRASIL. Ministério da Agricultura e Reforma Agrária. Regras para análise de sementes. Brasília: SNDA/DNDV/CLAV, 1992. 365p.
FALLERI, F. Effect of water stress on germination in six provenances of Pinus pinaster Ait. Seed Science and Technology, v.22, n.3, p.591-599, 1994.

MARCOS FILHO, J. Teste de envelhecimento acelerado. In: KRZYZANOWSKI, F.C. et al. Vigor de sementes: conceitos e testes. Associação brasileira de tecnologia de sementes. Comitê de vigor de sementes. Londrina: ABRATES, 1999. Cap.3, p.124.

MAYER, A.M.; POLJAKOFF-MAYBER, A. The germination of seeds. Oxford: Pergamon, 1989. 270p.

MORAES, G.A.F.; MENEZES, N.L. Desempenho de sementes de soja sob condições diferentes de potencial osmótico. Ciência Rural, v.33, n.2, p.219-226, 2003.

PESKE, S.T.; DELOUCHE, J.C. Semeadura da soja em condições de baixa umidade do solo. Pesquisa Agropecuária Brasileira, v.20, n.1, p.69-85, 1985.

SANTOS, V.L.M. et al. Efeito do estresse salino e hídrico na germinação e vigor de sementes de soja. Revista Brasileira de Sementes, v.14, n.2, p.189-194, 1992.

SANTOS, V.L.M. et al. Utilização do estresse salino na avaliação da qualidade de genótipos de soja (Glycine max L. Merrill). Revista Brasileira de Sementes, v.18, n.1, p.63-72, 1996.

VIEIRA, R.D.; KRZYZANOWSKI, F.C. Teste de condutividade elétrica. In: KRZYZANOWSKI, F.C. et al. Vigor de sementes: conceitos e testes. Associação brasileira de tecnologia de sementes. Comitê de vigor de sementes. Londrina: ABRATES, 1999. Cap.4, p.1-26.

VILLELA, F.A. et al. Tabela de potencial osmótico em função da concentração de polietilenoglicol 6000 e da temperatura. Pesquisa Agropecuária Brasileira, v.26, n.11/12, p.19571968, 1991.

WENKERT, W. et al. Leaf elongation and turgor pressure in field grown soybean. Agronomy Journal, v.70, n.5, p.761764, 1978. 